\title{
The efficacy of magnetic resonance cholangiopancreatogra- phy in assessing the etiology of acute idiopathic pancreatitis
}

\author{
Yattoo GN, Waiz Gowhar Amin, Feroze A Shaheen, Showkat Zargar, \\ Gul Javid
}

\section{ABSTRACT}

Aims: Idiopathic pancreatitis may be diagnosed once all causes of pancreatitis are excluded by thorough history, metabolic profile and conventional imaging modality, i.e., abdominal ultrasonography. In this study, we have attempted to evaluate the cause of idiopathic pancreatitis with the help of magnetic resonance cholangiopancreatography (MRCP). Methods: Fifty patients presenting with idiopathic pancreatitis were assessed prospectively using MRCP with strength 1.5 Tesla for potential cause of the attack of pancreatitis. Results: Magnetic resonance cholangiopancreatography was able to establish the cause of pancreatitis in eleven (22\%) patients, as follows. Common bile duct stone in one (2\%), pancreatic divisum in one (2\%), gallbladder stone in one (2\%), pancreatic duct stone in one (2\%), chronic pancreatitis in two (4\%), gallbladder sludge in two (4\%) and anomalous pancreaticobiliary union in three

Yattoo GN1, Waiz Gowhar Amin², Feroze A Shaheen ${ }^{3}$, Showkat Zargar ${ }^{4}$, Gul Javid ${ }^{4}$

Affiliations: ${ }^{1}$ Professor, Department of Gastroenterology, Sher-i-Kashmir Institute of Medical Sciences (SKIMS), Srinagar, Kashmir, India; ${ }^{2} \mathrm{MD}$, Internal Medicine, Department of Gastroenterology, Sher-i-Kashmir Institute of Medical Sciences (SKIMS), Srinagar, Kashmir, India; ${ }^{3}$ Professor, Radiology, Department of Gastroenterology, Sher-i-Kashmir Institute of Medical Sciences (SKIMS), Srinagar, Kashmir, India; ${ }^{4}$ Professor Gastroenterology, Department of Gastroenterology, Sher-i-Kashmir Institute of Medical Sciences (SKIMS), Srinagar, Kashmir, India.

Corresponding Author: Waiz Gowhar Amin, MD, Internal Medicine,Department of Gastroenterology, Sher-i-Kashmir Institute of Medical Sciences (SKIMS), Srinagar, Kashmir, India; Email:waizgowhar@rediffmail.com

Received: 05 May 2014

Accepted: 23 May 2014

Published: 31 July 2014
(6\%) patients. Conclusion: Magnetic resonance cholangiopancreatography, a non-invasive and complication free imaging modality is able to establish the cause of acute pancreatitis in patients in whom the diagnosis of idiopathic pancreatitis has been made following standard investigations. Idiopathic pancreatitis should not be diagnosed unless MRCP has been performed.

Keywords: Idiopathic pancreatitis, Pancreatitis, Causes of pancreatitis, Magnetic resonance cholangiopancreatography (MRCP)

\section{How to cite this article}

Yattoo GN, Amin WG, Shaheen FA, SZargar $\mathrm{S}$, Javid G. The efficacy of magnetic resonance cholangiopancreatography in assessing the etiology of acute idiopathic pancreatitis. Int $\mathrm{J}$ Hepatobiliary Pancreat Dis 2014;4:32-39.

Article ID: 100018IJHPDGN2014

$* * * * * * * * *$

doi:10.5348/ijhpd-2014-18-OA-6

\section{INTRODUCTION}

Acute pancreatitis is a common disease that causes significant morbidity and mortality throughout the world. The most common etiological factors for acute pancreatitis are cholelithiasis and alcohol (70-75\%) [1]. Other less common causes for acute pancreatitis include iatrogenic causes such as endoscopic retrograde cholangiopancreatography (ERCP), abdominal surgery, trauma, hypertriglyceridemia, hypercalcemia, drug induced, autoimmune, genetic, ischemic, various infections, congenital pancreatic divisum, microlithiasis/ 
sludge. Determining the cause of pancreatitis is an essential component of diagnostic evaluation. Since, the cause guides the management thereby allows elimination of precipitant and prevention of disease recurrence. Besides this, different causes have different natural histories with different complications, e.g., alcohol versus biliary pancreatitis. Furthermore, certain causes of pancreatitis have long-term consequences, e.g., pancreatic cancer associated with hereditary pancreatitis.

Apart from routine evaluation for the cause of pancreatitis, e.g., serum amylase, serum calcium and triglyceride levels, abdominal ultrasonography, an unexplained pancreatitis should be evaluated aggressively as there can be grave consequences associated with idiopathic pancreatitis. Idiopathic pancreatitis forms the largest subgroup (40\%) of all acute pancreatic fatalities $[2,3]$. Furthermore, over $50 \%$ of untreated patients with acute idiopathic pancreatitis experience recurrence [4-6], recurrent pancreatitis may progress to chronic pancreatitis with irreversible morphologic and functional changes $[7,8]$. Repeated hospitalization for pancreatitis is also associated with loss of health care resources. On initial negative evaluation other investigations including endoscopic retrograde cholangiopancreatography (ERCP), Magnetic resonance cholangiopancreatography (MRCP) and sphincter of Oddi manometry may be used. In this study, we have attempted to evaluate the patients of idiopathic pancreatitis with MRCP, which is non-invasive and apparently complication free imaging modality.

Magnetic resonance cholangiopancreatography is a non-invasive imaging technique which does not involve exposure to ionizing radiation. It can produce images comparable to those obtained by invasive investigations such as ERCP without its associated risks including pancreatitis, perforation of biliary or pancreatic ducts or bowel perforation and risks of intravenous contrast agents required for ERCP. Magnetic resonance cholangiopancreatography uses heavily T2weighted sequences by which the signal of static or slowly moving fluid in structures such as biliary and pancreatic ducts is greatly increased leading to increase in duct-to-background contrast. Magnetic resonance cholangiopancreatography can be used to investigate the cause of idiopathic pancreatitis in a non-invasive manner.

\section{MATERIALS AND METHODS}

The study was conducted by Department of Gastroenterology at tertiary care hospital from May 2011 to October 2013. During this period, 355 patients were admitted in the department with diagnosis of pancreatitis on the basis of history, physical findings, and evidence of elevation of serum amylase level. Amylase level of three fold the upper limit of normal serum level was taken as significant to qualify for diagnosis of pancreatitis and abdominal ultrasonography.

In $300(84.5 \%)$ patients cause of pancreatitis could be established, based on history, metabolic profile (hypercalcemia, hypertriglyceridemia) and ultrasonography of abdomen (Table 1). In rest of $55(15.5 \%)$ pancreatitis patients cause could not be determined. Therefore, 55 patients were diagnosed as idiopathic pancreatitis. Of these idiopathic pancreatitis patients five patients were excluded from the study because of the following reasons. Two patients because of claustrophobia, two patients did not give consent and one had the contraindication to MRCP in the form of permanent pacemaker implantation, hence, our study population of idiopathic pancreatitis comprised only 50 patients. Inclusion criteria included patient with idiopathic pancreatitis and written informed consent for study, exclusion criteria consisted of patients with absolute contraindication to MRCP, alcoholics, abdominal trauma, Post-ERCP, family history of pancreatitis, recent offending drug intake, hypercalcemia, hypertriglyceridemia, severe sepsis.

Idiopathic pancreatitis was defined as wherein cause of pancreatitis could not be established on thorough history, metabolic profile, X-ray abdomen and abdominal ultrasonography. For further assessment of etiology 50 patients with idiopathic pancreatitis were subjected to MRCP.

Magnetic resonance cholangiopancreatography was performed with $1.5 \mathrm{~T}$ (Siemens, Germany) with a phased array multi coils. All sequences were performed during breath holding for 12 seconds. Heavily T2-weighted sequences were obtained in the coronal and axial planes. Magnetic resonance cholangiopancreatography was interpreted prospectively by two experienced radiologists in relation to detectable abnormalities. Data were analyzed in SPSS 11.17 with respect to detectable abnormalities.

\section{RESULTS}

Fifty patients with idiopathic pancreatitis were studied in which twenty-two (44\%) were males and twenty-eight $(56 \%)$ were females with the age ranging

Table 1: Etiological profile of 355 patients of pancreatitis.

\begin{tabular}{lcc} 
Etiology of Subjects & Frequency & Percent \\
Gallstone & 256 & $72.0 \%$ \\
Worm induced & 15 & $4.2 \%$ \\
Chronic pancreatitis & 12 & $3.4 \%$ \\
Post-ERCP & 8 & $2.2 \%$ \\
Alcohol & 5 & $1.4 \%$ \\
Hypercalcemia & 4 & $1.1 \%$ \\
Idiopathic & 55 & $15.5 \%$ \\
Total & 355 & $100 \%$ \\
\hline
\end{tabular}


from 15-75 years mean age of 44 years. All these patients presented with two main symptoms, abdomen pain in $80 \%$ and combination of pain and vomiting in $20 \%$. For further assessment of etiology of pancreatitis, 50 patients with idiopathic pancreatitis were subjected to MRCP. The MRCP was able to detect the cause of pancreatitis in $\mathbf{1 1}$ (22\%) out of 50 patients of idiopathic pancreatitis which are given in Table 2.

In one ( $2 \%$ ) out of 50 idiopathic pancreatitis patients, stone was evident as a dark filling defect at lower end of common bile duct (CBD) which was retrieved at ERCP and endoscopic sphincterotomy (Figure 1).

In one (2\%) out of 50 idiopathic pancreatitis patients, complete pancreatic divisum was diagnosed at MRCP. The patient was managed conservatively and is on followup from last 20 months without any further episodes of pancreatitis (Figure 2).

Gallstone was detected in one (2\%) out of 50 idiopathic pancreatitis patients which was confirmed at subsequent cholecystectomy (Figure 3).

In one (2\%) out of 50 idiopathic pancreatitis patients, a solitary stone in the pancreatic duct was detected at MRCP (Figure 4).

In two (4\%) out of 50 idiopathic pancreatitis patients, MRCP appearances were consistent with chronic pancreatitis, the changes were consistent with early chronic pancreatitis, in these patients we will have to rely on observation over a long period of time than the 16-18 months follow-up currently available.

Gallbladder sludge, was diagnosed in two (4\%) out of 50 idiopathic pancreatitis patients which latter underwent laparoscopic cholecystectomy (Figure 5).

In three (6\%) out of 50 idiopathic pancreatitis patients, anomalous pancreaticobiliary union (APBU) was diagnosed at MRCP, one of patients among three underwent endoscopic sphincterotomy, in view of frequent episodes of pancreatitis (Figure 6).

Table 2: Frequency distribution of various etiologies detected at MRCP.

\begin{tabular}{lll} 
Etiology & Frequency & Percentage \\
\hline Idiopathic & 39 & 78.0 \\
$\begin{array}{l}\text { Anomalous pancreaticobiliary } \\
\text { union }\end{array}$ & 3 & 6.0 \\
Chronic pancreatitis & 2 & 4.0 \\
Pancreatic divisum & 1 & 2.0 \\
Common bile duct stone & 1 & 2.0 \\
Main pancreatic duct stone & 1 & 2.0 \\
Gallbladder sludge & 2 & 4.0 \\
Gallstone & 1 & 2.0 \\
Total & 50 & 100.0 \\
\hline
\end{tabular}

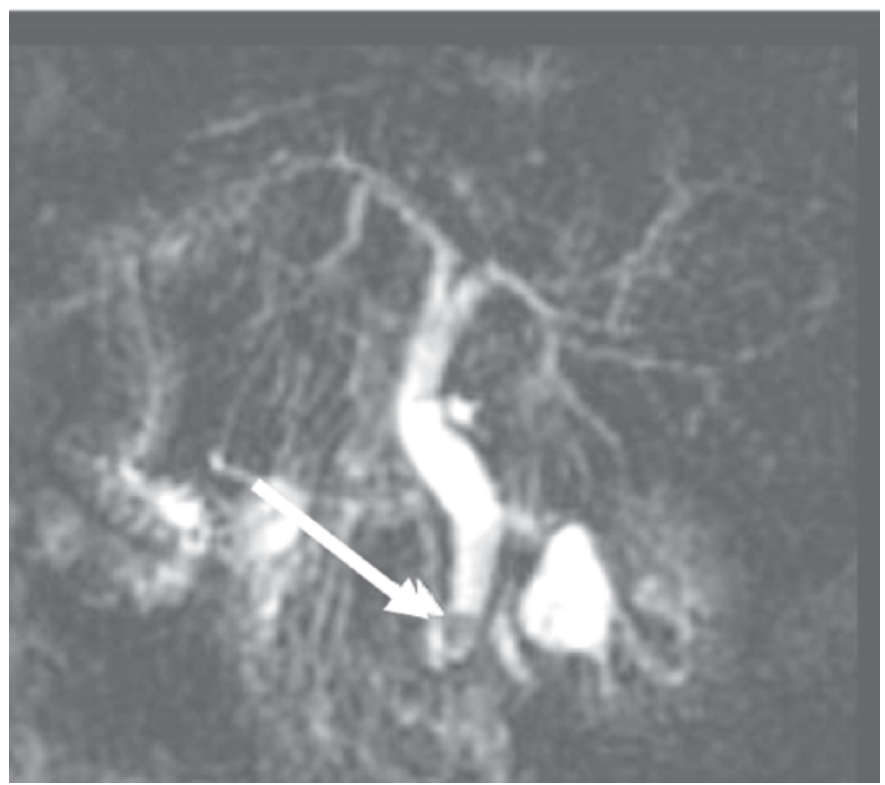

Figure 1: 38-year-old female with common bile duct stone.

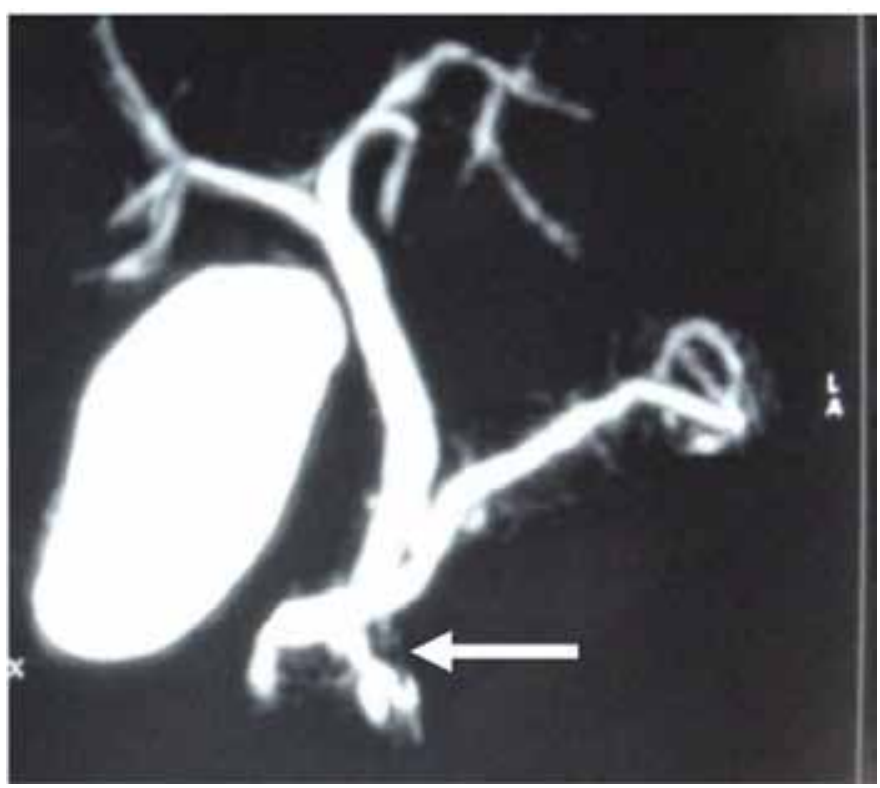

Figure 2: Pancreas-division in a 47-year-old female.

In the rest 39 (78\%) idiopathic pancreatitis patients, MRCP changes consistent with acute pancreatitis (edematous pancreas) were identified, without any cause. The MRCP detected the cause of acute pancreatitis in 11 (22\%) out of 50 idiopathic pancreatitis patients.

\section{DISCUSSION}

In up to $10 \%$ of patients with a single episode of acute pancreatitis and in $30 \%$ of patients with acute recurrent pancreatitis etiology is not found after initial 
evaluation $[9,10]$. It is recognized that further evaluation of patients with idiopathic pancreatitis may disclose evidence of potential etiology, such as unrecognized gallstone disease, CBD stone, chronic pancreatitis, APBU so that subsequent definitive management can be offered to the patients in order to prevent the morbidity and mortality associated with pancreatitis. In our study which comprised 50 patients of idiopathic pancreatitis, we attempted to assess the utility of MRCP in evaluating the cause of idiopathic pancreatitis.

An MRCP is a non-invasive exploration which has also proved its value in diagnosing entities responsible for an attack of acute pancreatitis such as choledocholithiasis, chronic pancreatitis, pancreatic duct strictures or stones,

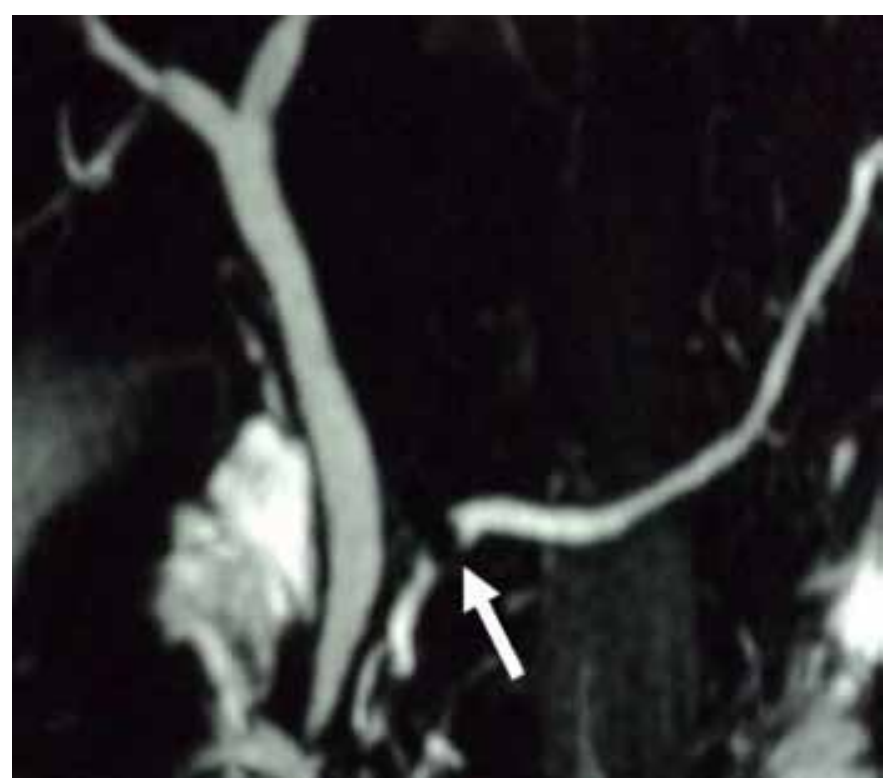

Figure 3: A 34-year-old female with main pancreatic duct stone.

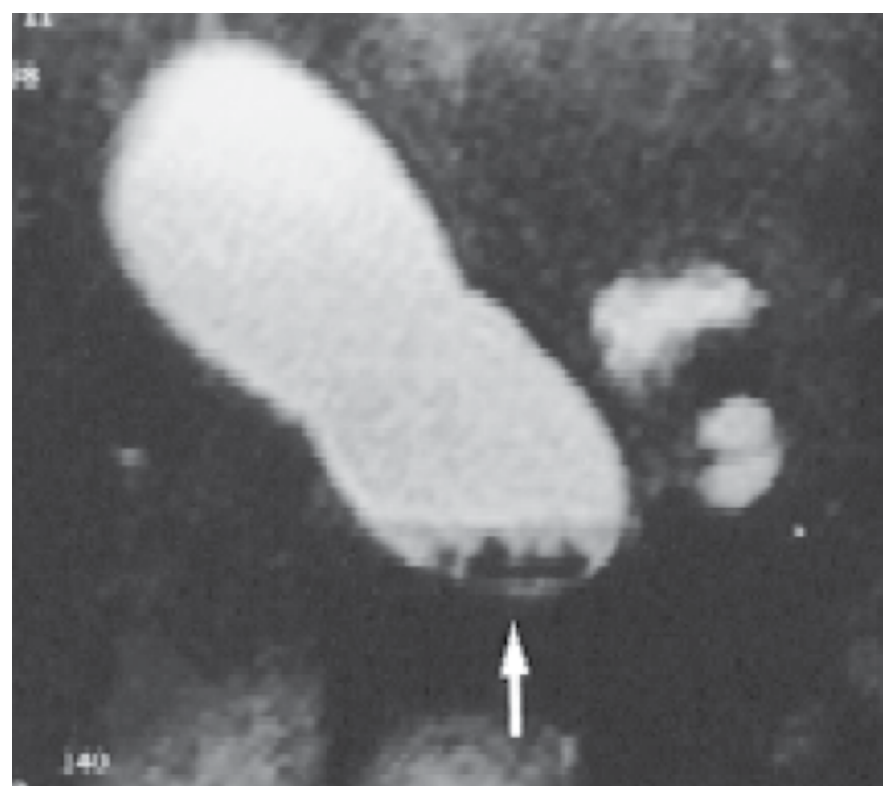

Figure 4: Magnetic resonance cholangiopancreatography showing gallbladder stone in a 41-year-old male. sphincter of Oddi dysfunction and anatomic anomalies [11-17].

The diagnostic accuracy of MRCP for choledocholithiasis is very high ranging between sensitivity $81-95 \%$ and specificity $85-98 \%$ as reported by several studies and with positive predictive value and negative predictive value from $82-100 \%$ and $94-100 \%$, respectively. Despite the accuracy of sonography and computed tomography scan, these imaging modalities are inferior to MRCP in diagnosis of choledocholithiasis [12-14]. Moon et al. in their study on bile duct stones in suspected biliary pancreatitis revealed that overall agreement between MRCP and ERCP was 90.6\% for detection of bile duct stones and concluded that MRCP

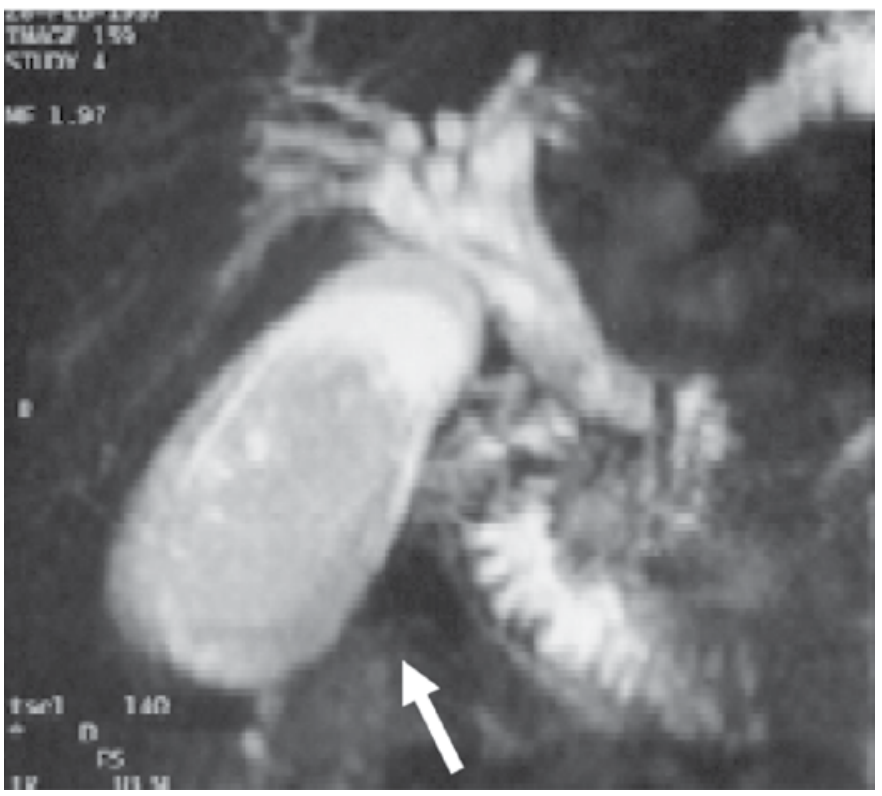

Figure 5: Gallbladder sludge in a 39-year-old female.

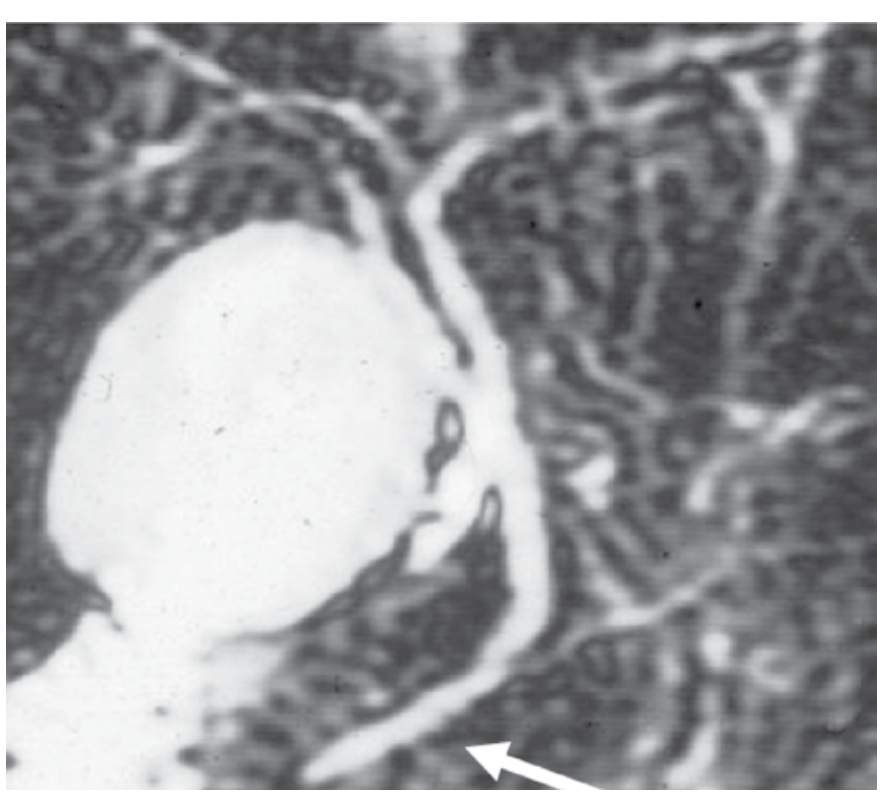

Figure 6: Long common channel in a 18-year-old male. 
can be used to select patients with biliary pancreatitis who require ERCP for intervention [18]. Mohan et al. while evaluating the relative roles of MRCP and EUS in investigating CBD calculi "evidence based practice" methods concluded MRCP should be the first line of investigation of CBD calculi [19]. The frequency and morbidity of recurrent pancreatitis are great, as undiagnosed biliary disease carries a recurrence rate of $20-50 \%$, whereas the risk of recurrent pancreatitis associated with biliary stones decreases to less than $5 \%$ after corrective surgery [20, 21].

Choledocholithiasis detected in one (2\%) out of 50 idiopathic pancreatitis patients was later confirmed at ERCP and subsequent stone extraction.

Pancreatic divisum occurs as an anatomic variant in $5-7.5 \%$ of patients $[5,21]$. At MRCP one $(2 \%)$ out of 50 idiopathic pancreatitis patients was diagnosed to have complete pancreatic divisum in our study. Bret et al. have shown that MRCP has 100\% accuracy for the detection of pancreatic divisum [16]. In the past, pancreatic divisum was established with ERCP. However, MRCP is preferred in the evaluation of pancreatitis with suspected pancreatic divisum because of risk of inducing or exacerbating pancreatitis.

Gallstone in one ( $2 \%$ ) out of 50 idiopathic pancreatitis patients was detected at MRCP in our study which was confirmed at subsequent cholecystectomy. One (2\%) out of 50 idiopathic pancreatitis patients was diagnosed as having pancreatic duct stone seen as dark round filling defect surrounded by high signal intensity pancreatic fluid. Recently, MRCP has been used for diagnosing chronic pancreatitis [22]. Sugiyama et al. in their study showed that MRCP well demonstrates dilatation, stricture and irregularity of MPD as well as filling defects due to stones and protein plugs in chronic pancreatitis [23]. Hagen et al. concluded that secretin administration further enhances MRCP value for diagnosis of chronic pancreatitis. They showed that secretin administration not only improves the visibility of pancreatic duct but also its side branches thereby increasing the diagnostic accuracy of MRCP in chronic pancreatitis [24].Therefore, MRCP may be useful for diagnosis of chronic pancreatitis. In our study, we diagnosed two (4\%) out of 50 idiopathic pancreatitis patients as having chronic pancreatitis which was of mild grade as per Cambridge classification.

In our study, two (4\%) out of 50 idiopathic pancreatitis patients MRCP identified biliary sludge as a cause of pancreatitis, these patients latter underwent laparoscopic cholecystectomy. Biliary lithiasis is an important cause of morbidity throughout the world. Ultrasonography is the diagnostic method of choice in such patients as it is rapid, non-invasive, highly sensitive and specific (>95\%) in establishing the presence and absence of gallbladder stones more than $2 \mathrm{~mm}$ in diameter $[25,26]$.

Biliary sludge is sometimes difficult to diagnose and represents the cause of more than half of all cases of acute idiopathic pancreatitis [10, 27-29]. In these cases invasive procedures are required such as duodenal catheterization, ERCP mediated bile aspiration [30].

Anomalous union of the pancreatic and bile ducts is seen in $1.5-3 \%$ of individuals. The union is characterized by an unusually long ( $>15 \mathrm{~mm}$ ) channel common to the two ducts that lies proximal to the sphincters of the pancreatic and bile ducts in the duodenal wall. Two-way regurgitation occurs and allows reflux of bile into the pancreatic duct because the action of the sphincter does not functionally affect the union. This results in frequent attacks of pancreatitis. The diagnosis of pancreaticobiliary malformation is confirmed by visualizing the biliary and pancreatic ductal systems on ERCP. Currently, MRCP is becoming one of the first choices in evaluation of pancreaticobiliary malformation in a non-invasive manner [24, 27]. The MRCP allows complete anatomical analysis of whole pancreaticobiliary tree to precise the size and morphological characteristic of CBD (sensitivity 100\%) and for pancreaticobiliary malformation (sensitivity 69\%) hence may replace the ERCP for diagnostic evaluation. The study performed on 32 subjects by Kamisava et al. concluded that conventional MRCP is quite useful tool for diagnosis of congenital pancreaticobiliary malformation though diagnostic accuracy can be enhanced with three-dimensional MRCP or MRCP with secretin administration [31]. In our study, diagnosis of APBU was made at MRCP in three (6\%) out of 50 idiopathic pancreatitis patients in the form of long common channel with $16 \mathrm{~mm}, 16.5 \mathrm{~mm}$ and $18 \mathrm{~mm}$ as dimensions. One of these patients had multiple episodes of pancreatitis, since he was diagnosed, who underwent endoscopic sphincterotomy later.

In our study, one ( $2 \%$ ) out of 50 idiopathic pancreatitis patients suffered from repeated episodes of pancreatitis the patient was subjected to ERCP and stone was retrieved out ampullary area.

In 39 ( $78 \%$ ) out of 50 idiopathic pancreatitis MRCP could not detect any cause of pancreatitis. We assume that many of these patients would have ascariasis as cause of pancreatitis, as worm infestation is highly prevalent in this part of world, since ascariasis induced pancreatitis was shown to have incidence of $23 \%$ by Khuroo et al. in their study [32]. By the time MRCP was done worms would have been already out of biliary and pancreatic ducts. Furthermore, evaluation for Oddi dysfunction, bile aspiration for biliary sludge, genetic studies or autoimmune pancreatitis may be needed to establish the etiology in remaining cases.

Alcohol induced pancreatitis was quite less (1.4\%) in our study as compared to reported in other literatures, the reason is obvious since alcohol consumption is very little in this part of the world due to cultural and religious implications.

\section{CONCLUSION}

As knowledge and technology advances, the true idiopathic pancreatitis is declining. Since, elucidation 
of cause of pancreatitis nowadays has become more obvious with the advancement of laboratory and imaging studies. Establishing etiology with a non-invasive magnetic resonance cholangiopancreatography (MRCP) could have a substantial effect on the management of acute idiopathic pancreatitis as it guides about the treatment, thereby reducing the morbidity and mortality associated with pancreatitis. The MRCP is relatively new diagnostic technique with several advantages over other invasive and non-invasive methods of imaging biliary and pancreatic ductal systems in pancreatitis. Magnetic resonance cholangiopancreatography is a promising tool for evaluating the patients with idiopathic pancreatitis as it is able to detect pathology in these patients even when standard imaging is unsuccessful. Therefore, we recommend the use of MRCP in pancreatitis before labeling it as an idiopathic pancreatitis.

$* * * * * * * * *$

\section{Author Contributions}

Yattoo GN - Substantial contributions ton conception and design, Acquisition of data, Drafting the article, revising it critically for important intellectual content, Final approval of the version to be published

WaizGowhar Amin - Substantial contributions ton conception and design, Acquisition of data, Drafting the article, revising it critically for important intellectual content, Final approval of the version to be published Feroze Shaheen - Substantial contributions ton conception and design, Acquisition of data, Drafting the article, Revising it critically for important intellectual content, Final approval of the version to be published Showkat A Zargar - Substantial contributions ton conception and design, Acquisition of data, Drafting the article, revising it critically for important intellectual content, Final approval of the version to be published Gul Javid - Substantial contributions ton conception and design, Acquisition of data, Drafting the article, Revising it critically for important intellectual content, Final approval of the version to be published

\section{Guarantor}

The corresponding author is the guarantor of submission.

\section{Conflict of Interest}

Authors declare no conflict of interest.

\section{Copyright}

(C) 2014 Yattoo GN et al. This article is distributed under the terms of Creative Commons Attribution License which permits unrestricted use, distribution and reproduction in any medium provided the original author(s) and original publisher are properly credited. Please see the copyright policy on the journal website for more information.

\section{REFERENCES}

1. Lankisch PG, Assmus C, Pflichthofer D, Struckmann $\mathrm{K}$, Lehnick D. Which etiology causes the most severe acute pancreatitis? Int J Pancreatol 1999;26(2):55-7.

2. Wilson C, Imrie CW, Carter DC. Fatal acute pancreatitis. Gut 1988;29(6):782-8.

3. Banerjee AK, Kaul A, Bache E, Parrberry AC, Doran J, Nicholson ML. An audit of fatal acute pancreatitis. Postgrad Med J 1995;71(838):472-5.

4. Venu RP, Geenen JE, Hogan W, Stone J, Johnson GK, Soergel K. Idiopathic recurrent pancreatitis. An approach to diagnosis and treatment. Dig diseases sci 1989;34(1):56-6o.

5. Bernard JP, Sahel J, Giovannini M, Sarles H. Pancreas divisum is a probable cause of acute pancreatitis: A report of 137 cases. Pancreas 1990;5(3):248-54.

6. Levy MJ, Geenen JE. Idiopathic acute recurrent pancreatitis. Am J Gastroenterol 2001;96(9):254055 .

7. Steer ML, Waxman I, Freedman S. Chronic pancreatitis. N Engl J Med 1995;332(22):1482-90.

8. Etemad B, Whitcomb DC. Chronic pancreatitis: Diagnosis, classification, and new genetic developments. Gastroenterology 2001;120(3):682707.

9. Steinberg W, Tenner S. Acute pancreatitis. N Engl J Med 1994;330(17):1198-210.

10. Lee SP, Nicholis JF, Park HZ. Biliary sludge as a cause of acute pancreatitis. N Engl J Med 1992;326(9):5893.

11. Fulcher AS, Turner MA, capps GW, Zfass Am, Baker KM. Half-Fourier RARE MR cholangiopancreatography: Experience in 300 subjects. Radiology 1998;207(1):21-32.

12. Guibaud L, Bret PM, Reinhold C, Atri M, Barkun AN. Bile duct obstruction and choledocholithiasis: Diagnosis with MR cholangiography. Radiology 1995;197(1):109-15.

13. Chan YL, chan AC, Lam WW, et al. choledocholithiasis: Comparison of MR cholangiography endoscopic retrograde cholangiopancreatography. Radiology 1996;200(1):85-9.

14. Regan F, Fradin J, Khazan R, Bohlman M, Magnuson T. Choledocholithiasis: Evaluation with MR cholangiography. AJR Am J Roentgenol 1996;167(6):1441-5.

15. Morimoto K, Shimoi M, Shirakawa T, et al. Biliary obstruction: Evaluation with three-dimensional MR cholangiography. Radiology 1992;183(2):578-80.

16. Bret PM, Reinhold C, Taourel P, Guibaud L, Atri M, Barkun AN. Pancreas divisum: Evaluation with MR cholangiopancreatography. Radiology 1996;199(1):99-103.

17. Taourel P, Bret PM, Reinhold C, Barkun AN, Atri M. Anatomic variants of he biliary tree: Diagnosis with MR cholangiopancreatography. Radiology 1996;199(2):521-7.

18. Moon JH, Cho YD, Cha SW, et al. The detection of bile duct stones in suspected biliary pancreatitis: Comparison of MRCP, ERCP, and intraductal US. Am J Gastroenterology 2005;100(5):1051-7.

19. McMahon CJ. The relative roles of magnetic resonance cholangiopancreatography and endoscopic ultrasound 
(EUS) in diagnosing CBD calculi. A critically upraised topic. Abdom Imaging 2008;33(1):6-9.

20. Ranson JH. The timing of biliary surgery in acute pancreatitis. Ann Surg 1979;189(5):654-3.

21. Cotton PB. Pancreas divisum. Am J Gastroenterol 1995;90(10):1898.

22. Sica GT, Braver J, Cooney MJ, Miller FH, Chai JL, Adams DF. Comparison of endoscopic retrograde cholangiopancreatography with MR cholangiopancreatography in patients with pancreatitis. Radiology 1999;210(3):605-10.

23. Sugiyama M, Haradome H, Atomi Y. Magnetic resonanceimaging for diagnosing chronic pancreatitis. J Gastroenterology 2007;42(Suppl 17):108-2.

24. Heverhagen JT, Burbelko M, Schenck zu Schweinsberg $\mathrm{T}$, et al. Secretin enhanced magnetic resonance cholangiopancreatography value for diagnosis of chronic pancreatitis. Rofo 2007;179(8):790-5. [Article in German].

25. De Dios JF, Mino G, HigadoY sistemabiliar. In Varas MJ, ed. Ultrasonographiadigestive.madrid: Ediciones Ergon SA 1996:5-18.
26. Cronan JJ. US diagnosis of choledocholithiasis: A reappraisal. Radiology 1986;161(1):133-4.

27. Ko CW, Sekijima JH, Lee SP. Biliary sludge. Ann Intern Med 1999;130(4 Pt 1):301-1.

28. Lee SP, Hayashi A, Kim YS. Biliary sludge: Curiosty or culprit? Hepatology 1994;20(2):523-5.

29. Lee SP. Pathogenesis of biliary sludge. Hepatology 1990;12(3 Pt 2):200S-3S.

30. Realini S, Pertoldi W, Cereda W, Imburgia L. Usefulness of bile analysis collected via endoscopy in the diagnosis of microlithiasis and biliary sludge. Praxis (Bern 1994)1994;83(45):1254-5. [Article in French].

31. Kamisawa T, Tu Y, Egawa N, Tsuruta K, Okamoto A, Kamata N. MRCP of congenital pacreaticobiliary malformation. Abdominal imaging 2007;32(1):12933 .

32. Khuroo MS, Zargar SA, Yattoo GN, et al. Ascariasis-induced acute pancreatitis. $\mathrm{Br} \mathrm{J}$ Surg 1992;79(12):1335-8.

\section{ABOUT THE AUTHORS}

Article citation: Yattoo GN, Amin WG, Shaheen FA, SZargar S, Javid G. The efficacy of magnetic resonance cholangiopancreatography in assessing the etiology of acute idiopathic pancreatitis. Int J Hepatobiliary Pancreat Dis 2014;4:32-39.

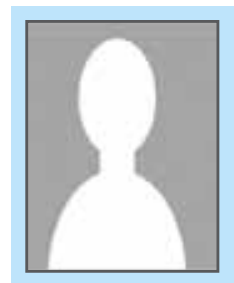

Yattoo GN is Professor, Department of Gastroenterology, Sher-i-Kashmir Institute of Medical Sciences (SKIMS), Srinagar, Kashmir, India.

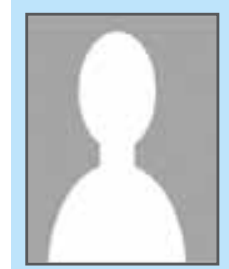

Waiz Gowhar Amin is Resident in Department of Internal Medicine at Skims Medical College Bemina Srinagar Kashmir, India. He earned the undergraduate degree MBBS from Department of Internal Medicine at Skims Medical College Bemina Srinagar Kashmir, India and postgraduate degree form MD from Department of Internal Medicine at Skims Medical College Soura Srinagar Kashmir, India. His research interests include Gasteroenterology. He intends to pursue Fellowship In Emergency Medicine in future.

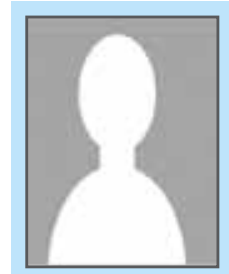

Feroze A Shaheen is Professor, Radiology, Department of Gastroenterology, Sher-i-Kashmir Institute of Medical Sciences (SKIMS), Srinagar, Kashmir, India. 


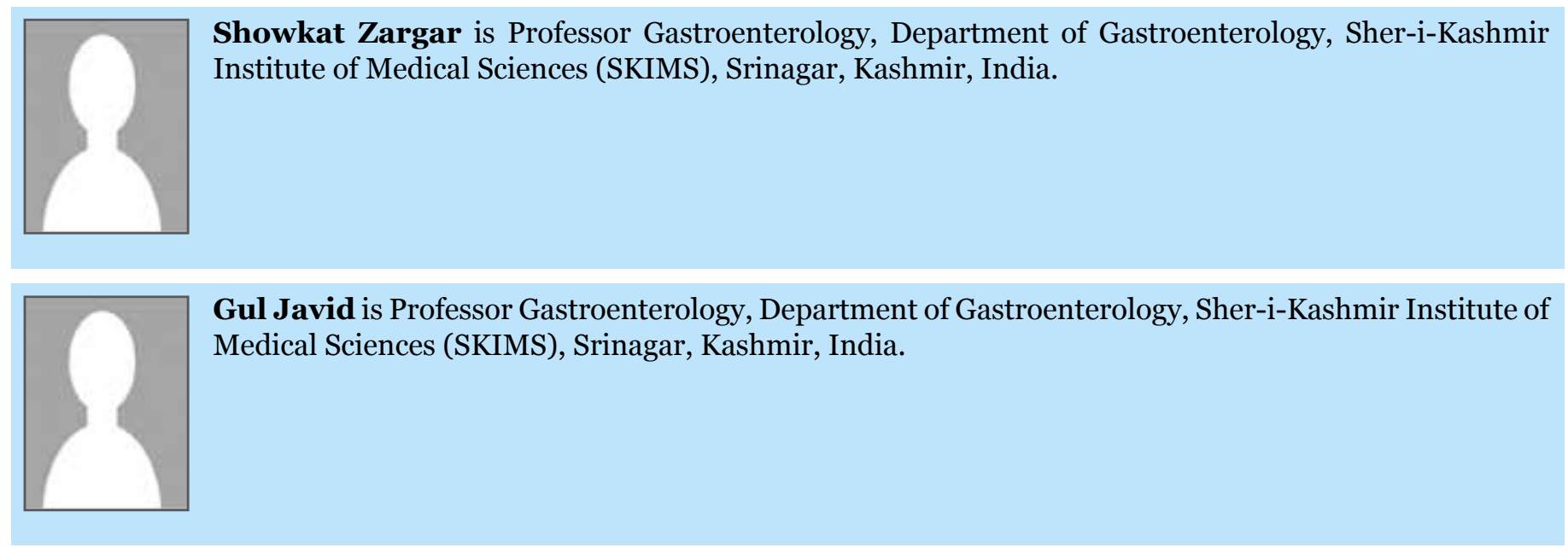

Access full text article on other devices

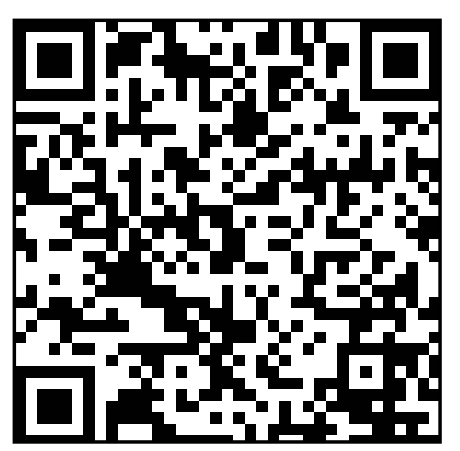

Access PDF of article on other devices

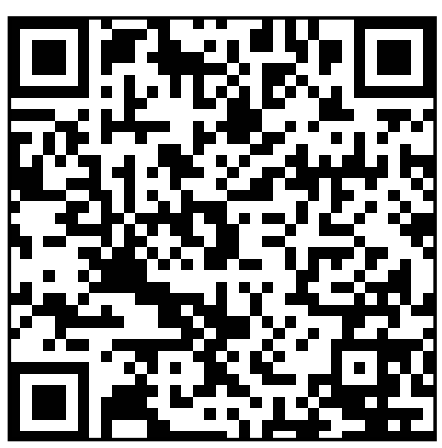

